\title{
Diagnosis and treatment of coeliac disease
} Karel Geboes ${ }^{1 *}$ and Karen P Geboes ${ }^{2}$

\author{
Address: ${ }^{1}$ Department of Pathology, University Hospital of Leuven, Minderbroedersstraat 12, 3000 Leuven, Belgium; ${ }^{2}$ Department of \\ Gastroenterology, Ghent University Hospital, De Pintelaan 185, B9000 Gent, Belgium \\ *Corresponding author: Karel Geboes (karel.geboes@uz.kuleuven.ac.be) \\ FI000 Medicine Reports 2009, I:32 (doi:I0.34I0/MI-32)
}

The electronic version of this article is the complete one and can be found at: http://FI000.com/Reports/Medicine/content/I/32

\begin{abstract}
It is now clearly established that coeliac disease is much more common than originally considered. While in the past it was taught that coeliac disease was mainly a disease of children, it is clear now that it may be diagnosed at any age. The clinical presentation of adolescents and adults is, however, less typical. Recent evidence suggests that coeliac disease is a multi-organ disease. The diagnostic techniques involving histology and serologic testing have been improved and the involvement of environmental and genetic factors in the pathogenesis of this immune disorder has been clarified, although the pathogenesis is not yet completely understood. Complications are now better identified, and new treatment strategies are under consideration.
\end{abstract}

\section{Introduction and context}

"There is a kind of chronic indigestion which is met in persons of all ages, yet is especially apt to affect children between one and five years old. Signs of the disease are yielded by the faeces; being loose, not formed, but not watery..." this is how Samuel Gee described gluten-enteropathy in his paper 'On the coeliac affection' [1]. He also acknowledged the findings of Aretaeus of Cappadocia who first wrote of coeliac disease as far back as the second century, and introduced the name 'koiliakos', a classic Greek term that stands for 'suffering in the bowels'. Over the last years it has become clear however, that the disease may not be limited to the bowel but affects also other systems.

As a result of the work of the Dutch paediatrician Dicke, a gluten-free diet was recommended as the standard treatment for the disease [2]. Standards for definition and diagnosis were introduced in the 1970s [3], and coeliac disease was defined by the European Society for Paediatric Gastroenterology and Nutrition (ESPGAN) as a 'small intestinal mucosal lesion (villous atrophy) associated with malabsorption and improvement with dietary gluten withdrawal'.

\section{Pathogenesis}

Coeliac disease is a chronic inflammatory or immune disease of the small intestine triggered by dietary proteins in wheat, rye and barley in genetically susceptible individuals. Therefore, both environmental and genetic factors play an important role in the pathogenesis. The disease-activating proteins from the environment are collectively termed 'gluten', but related prolamins can also trigger the disease. The term 'gluten' refers to the entire protein component of wheat, which comprises gliadin and glutenin. Gliadin is the alcohol soluble fraction that contains the bulk of the toxic components. Undigested molecules of gliadin, such as a peptide from an $\alpha$-gliadin fraction, are resistant to degradation and linger in the intestinal lumen before passing through the epithelial barrier and interacting with antigen-presenting cells, thereby promoting an inflammatory reaction.

The concordance for coeliac disease of $75-80 \%$ between monozygotic twins stresses the importance of genetic factors, but the genetics of coeliac disease is complex [4]. The main genetic risk factors are the human leukocyte antigen (HLA)-DQ2/8 genotypes, which are thought to account for $40 \%$ of the genetic predisposition [5]. 
Coeliac disease originates as a result of a combined action involving both adaptive and innate immunity, but the precise pathway or pathways are not yet completely identified. Immunological studies of the disease have shown that the immunodominant dietary peptides' (wheat gliadin) resistance to intestinal enzymatic breakdown, the modification of peptides by tissue transglutaminase (tTG) and the presentation of peptides to T cells by HLA-DQ molecules are all key steps leading to the intestinal inflammatory response. The disease associated HLA-DQ2 molecule has special features such as the presence of several 'pockets' that favour binding of negatively charged residues, such as those found in gluten peptides. The enzyme tTG can modify gluten peptides, so that they can bind to HLA-DQ molecules and trigger the inflammatory T-cell response. The HLADQ2 and HLA-DQ8 molecules predispose individuals to coeliac disease by preferential presentation of gluten peptides to CD4+ T-cells. The activated HLA-DQ2 or HLA-DQ8 restricted T-cells produce mainly Thelper (Th) 1 type cytokines, most notably interferon-gamma (IFN- $\gamma$ ), leading to the production of autoantibodies such as anti-tTG. Gliadin peptides also activate an innate immune response in the intestinal epithelium [6].

\section{Epidemiology and clinical presentation}

Four possible presentations of coeliac disease are recognized: typical presentation with gastrointestinal signs and symptoms (usually malabsorption, steatorrhoea, and abdominal distention); atypical or extraintestinal presentation, where gastrointestinal symptoms are minimal or absent but extraintestinal manifestations prevail (such as anemia, osteoporosis, short stature, and infertility); silent disease, where the small intestine is damaged and serology positive but symptoms are not present; and latent or potential disease, where individuals possess genetic characteristics but present with a normal mucosa, may or may not be symptomatic, and may show positive serology.

\section{Diagnosis}

The single most important step in diagnosing coeliac disease is to first consider the possibility. There is no one test that can completely exclude or diagnose coeliac disease with $100 \%$ certainty because, just as there is a continuum in the clinical spectrum, there is also a continuum in histopathologic and laboratory results. All diagnostic tests need to be performed while the patient is on a gluten-containing diet.

The widespread availability of serologic tests has permitted any physician to test for coeliac disease. The detection of autoantibodies is often used as a first-line test to identify individuals who might require a duodenal biopsy. EMA (endomysial antibodies) and tTG are currently the most recommended tests. The sensitivity (+/- $93.9 \%)$ and specificity $(96.5 \%)$ of the second generation of immunoglobulin A (IgA) anti-tTG assays are good [7], whereas there are reports of positive tTG tests in the absence of coeliac disease [8] (which can be seen in those with type 1 diabetes, chronic liver disease, heart failure and psoriatic or rheumatoid arthritis). It has been suggested that in some patients, proteins other than tTG may act as antigens for anti-tTG antibodies. It has also been suggested that in coeliac disease patients with subtle lesions, the serology can even be negative [9].

Small intestinal biopsy examination is the gold standard for diagnosis. Biopsies of the descending duodenum, rather than the more distal intestine, seem sufficient for the diagnosis of coeliac disease, with jumbo forceps having no marked advantage over standard size forceps [10]. Due to the patchy nature of villous changes, multiple biopsies are necessary, therefore it has been suggested that at least four endoscopic biopsies must be taken $[11,12]$. Ideally, the specimens should be orientated properly in order to allow adequate assessment of villous height and crypt depth. Based on the development pattern of coeliac lesions and on the frequent finding of cases with mild lesions, Marsh [13] proposed a four stage classification: type 1 infiltrative lesion, a normal mucosal architecture with an increased number of intra-epithelial lymphocytes (IELs); type 2 hyperplastic lesion, an increase in crypt depth without villous flattening; type 3 destructive lesion, showing villous atrophy and crypt hypertrophy; and type 4 hypoplastic lesion, with villous atrophy, normal crypt height and IEL count. Oberhuber et al. [14] and Corazza and Villanacci [15] subsequently proposed modified schemes.

A major pitfall in diagnosis is the over-interpretation of villous morphology, which can be attributed to tangential sectioning. The recognition of the spectrum of histological changes in coeliac disease as classified by Marsh, or modifications of this classification, has provided a major advantage in the diagnosis. The earliest lesions still have a normal villous architecture but show intra-epithelial lymphocytosis. In coeliac disease the IEL count is more than 30 or 40 per 100 epithelial cells (normally lower than 20) [16].

The HLA-DQ2 genotype is found in up to $90-95 \%$ of patients with coeliac disease, while most of the remaining patients have HLA-DQ8 [17]. In difficult cases, determination of HLA-DQ may aid diagnosis, but it may be not give a definite answer because these HLA alleles are found in up to $40 \%$ of the general population. 
However, absence of HLA-DQ2 or DQ8 virtually excludes a diagnosis of coeliac disease, apart from in very rare cases.

\section{Complications}

Complications typically occur after many years of disease, usually in adults. Coeliac disease carries an increased risk for lymphoma, usually of T cell origin. The associated high-grade lymphoma is known as enteropathy-associated T-cell lymphoma (EATL). There is also an increased risk of adenocarcinoma of the small intestine and possibly elsewhere in the gastrointestinal tract. All-cause mortality among those with clinically diagnosed coeliac disease is about twice that of a control population [18].

\section{Treatment}

The cornerstone of treatment for coeliac disease is a lifelong gluten-free diet devoid of proteins from wheat, barley, rye and related cereals. Even small quantities of gluten may be harmful. Oats are tolerated by most patients but can cause problems in some. There are considerable differences between individual patients with respect to clinical and mucosal responses to gluten challenge.

\section{Recent advances \\ Pathogenesis \\ Genetics}

Recent genome-wide association studies point to a large number of predisposing variants, each confering a risk of variable size. The provisional list of predisposing loci includes known CELIAC1 on chromosome 6 (HLA-DQ2 and HLA-DQ8), CELIAC2 on chromosome 5q31-33, CELIAC3 on chromosome 2q33 (containing T-lymphocyte regulatory genes CD28, CTLA4 and ICOS), and CELIAC4 (the myosin IXB gene, MYO9XB) on chromosome 19p13.1. It has been hypothesized that this latter genetic variant might lead to an impaired intestinal barrier $[19,20]$. Furthermore, associations with tight junction genes PARD3 and MAG12 have been reported. Genome-wide association studies also identified risk variants in the 4q27 region harbouring IL2 and IL21 genes, and other regions harbouring genes controlling immune responses, for example, leukocyte signalling in response to IL-18 and IFN- $\gamma$ production $[21,22]$.

From these studies it appears that the genetic predisposition to coeliac disease depends on one gene with a large effect on the adaptive immune response to gluten peptides (HLA-DQ2/DQ8) and many other genes influencing different aspects of innate and adaptive immune reactions, intestinal permeability and predisposition to autoimmunity $[23,24]$. It also appears that coeliac disease and type 1 diabetes share HLA-DQ, IL2-IL21, CCR3 and SH2B as risk factors [24,25].

\section{Immunology}

How Th1 cells are induced and maintained in the mucosa has not been clear in the past. However, recent data from duodenal mucosal biopsy studies suggest that IL-21 may play a role in maintaining and expanding the gluten-specific Th response [26]. Other data suggest that IFN- $\alpha$, produced by activated plasmacytoid dendritic cells in the mucosa, may be the cytokine responsible for polarizing the Th1 response. IFN- $\alpha$ can also upregulate the expression of IL-21 mRNA in human T cells stimulated via the T-cell receptor, so the interplay between IL-21 and IFN- $\alpha$ may amplify the Th1 response. IL-21 also interacts with IL-15 and they exert both opposing and synergistic effects at the interface between adaptive and innate immunity.

Some studies suggest that the innate immune component of coeliac disease may result from an inherent defect [abnormally increased expression of Toll-like receptor (TLR) mRNA for TLRs 2 and 4 in the mucosa of coeliac patients] [27]. This affects intestinal permeability and may promote activation of antigen-presenting cells.

The release of cytokines such as IFN- $\alpha$ and IL-15 and the expression of natural killer receptors at the surface of IELs that recognize non-classical major histocompatibility complex class I molecules (which are induced on the surface of enterocytes by stress and inflammation), are other mechanisms involved [28-30]. The interaction leads to the activation of the lymphocytes to become lymphokine-activated killing cells. IL-15 may promote the expansion of IELs via natural killer receptors and license their killing of enterocytes.

\section{Epidemiology and clinical presentation}

Recent findings estimate that about 1 in 133 people have coeliac disease in Europe and the USA, with about $2,000,000$ cases in the USA alone [31]. Most patients who are diagnosed with coeliac disease present as adults but family screening can identify 'silent disease' using a proactive case-finding strategy [32]. Studies have also shown that coeliac disease may be more common in Africa, South America, and Asia than previously believed. The occurrence of the disease can show an epidemic presentation such as that observed in Sweden in the mid-1980s. To explain the different epidemiologies in the Swedish epidemic, the model of an iceberg was proposed; the whole iceberg represented people with a genetic susceptibility, while the top represented symptomatic patients. Environmental exposures, including 
infant feeding practices, were also found to trigger the disease [33].

Typical presentations of diarrhoea and malabsorption are more common in childhood, being observed in almost $62 \%$ of the cases. Children also show a better histologic recuperation. Presentation during adolescence and adulthood is more atypical and can be oligosymptomatic in adolescents, with typical presentation observed in only $31 \%$ of adult patients [34]. Overall, the clinical presentation has changed over the years because the atypical forms are better recognized. Today, diarrhoea occurs in less than $50 \%$ of patients at presentation compared with nearly $100 \%$ of patients who presented in the 1960s. Weight loss is now an uncommon feature.

It is now known that coeliac disease may frequently co-exist with organ-specific or systemic autoimmune diseases, such as type 1 diabetes mellitus, thyroiditis, Sjögren's syndrome, and connective tissue diseases. Several hepatic disorders, including primary biliary cirrhosis, and especially those of autoimmune etiology, have also been described in patients with coeliac disease. In patients with type 1 diabetes mellitus or thyroiditis, screening may lead to a diagnosis of latent coeliac disease in $5-10 \%$ of patients [35]. Coeliac patients most at risk for autoimmune disease are those diagnosed early in life and those that have a family history of autoimmunity. It is not yet clear whether early diagnosis and treatment of coeliac disease may lead to a decreased incidence or a better clinical outcome of other autoimmune disorders [36].

\section{Diagnosis}

There have been several recent advances in diagnosing coeliac disease. For instance, it is now known that, typically, a high increase in IELs can also be seen at the top of the villi (Figure 1). The diagnostic yield will increase when immunohistochemistry with antibodies directed against $\mathrm{T}$ lymphocytes (CD3) is performed. Intra-epithelial lymphocytosis is not, however, specific for coeliac disease and may be seen in infective enteropathies, Crohn's disease, non-steroidal antiinflammatory drug usage, giardiasis and other conditions. Furthermore, coeliac disease is not the only possible cause of subtotal or total villous atrophy. Other possibilities such as autoimmune enteropathy, food intolerance, drug-use, radiation therapy and conditions such as Zollinger-Ellison syndrome must also be considered [37]. A recent study showed that, in difficult cases, measuring anti-tTG antibody levels produced in loco by the duodenal mucosa can help to establish the diagnosis [9].
Figure I. Small intestinal villus with increased number of IELs: Marsh classification type I (infiltrative lesion)

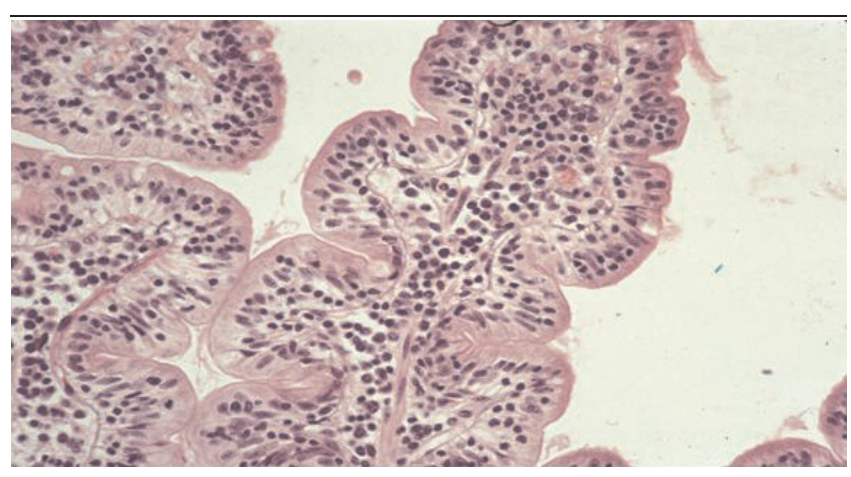

IEL, intra-epithelial lymphocyte.

Endoscopic evaluation can aid diagnosis but is not sufficient without biopsy [10]. Visible abnormalities that have been described include mucosal pallor, scalloping and a decrease in duodenal folds (Figure 2). The introduction of new endoscopic techniques such as confocal endomicroscopy may increase the diagnostic yield, although this is unlikely to solve the differential diagnostic issues.

Double-ballon enteroscopy improves the diagnosis of refractory coeliac disease (RCD), which is associated with complications such as ulcerative jejunitis and EATL, and allows the delineation of the extent of these complications.

\section{Complications}

A recent study found that the odds ratio for nonHodgkin lymphoma of any primary site associated with

Figure 2. Coeliac disease: endoscopy of the duodenum showing loss of normal folds

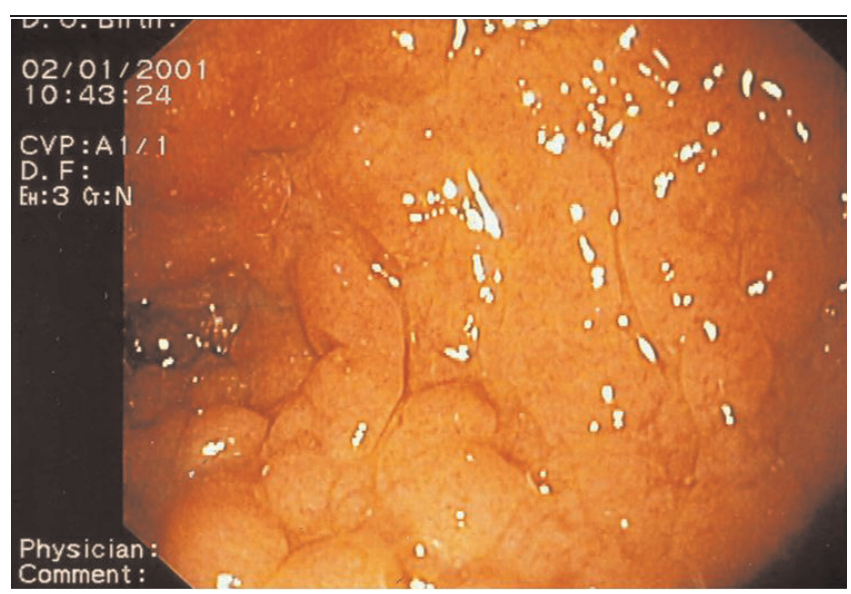


coeliac disease was found to be 3.1 times normal. For gut lymphoma the odds ratio was 16.9 and for T-cell lymphoma it was 19.2 [38]. In contrast, the increase in relative risk for EATL in coeliac disease is not precisely known because of its rarity; a recent study of the Dutch population found that EATL had an estimated incidence of 1 per 1,000,000 people per year. Deterioration of coeliac disease is thought to be the most frequent warning symptom of EATL [39]. Most EATLs are localized in the proximal small intestine, and the lymphoma may be multifocal, cause multiple ulcers, strictures or tumour nodules. Bone marrow aspiration and biopsy, as well as lumbar puncture, should be performed for staging the lymphoma [40]. Some evidence suggests that a gluten-free diet reduces lymphoma risk. In approximately $20 \%$ of the cases, the associated coeliac disease is clinically occult.

Approximately $5 \%$ of patients have RCD, defined as persistent symptoms and villous atrophy despite adherence to a gluten-free diet for more than 12 months. RCD may be subdivided into type I RCD, with normal IEL phenotype, and type II RCD, with abnormal clonal IEL type. Clonal refractory sprue (RCD II) is now considered as a low-grade T-cell lymphoma. It is often the first step of a transformation that may give rise to a high-grade lymphoma, and is characteristically associated with ulcerative jejunitis at endoscopy. At diagnosis, malnutrition and lymphocytic gastritis are more common.

Non-clonal refractory sprue (RCD I) is not associated with ulcerative jejunitis and more rarely complicated by a lymphoma. Two cases were observed in a series of 14 patients with RCD I, whereas 16 overt lymphomas were observed in a series of 43 patients with RCD II [41].

The distinction between RCD I and II is currently based on immunophenotyping of $\mathrm{T}$ cells by immunohistochemistry or flow-cytometric analysis of small bowel biopsies, which screen for the presence of a significant percentage of aberrant T cells. An abnormal phenotype of IELs is a predictive factor, but not a necessary condition, for the development of overt lymphoma [41]. For the management of RCD II, high dose chemotherapy followed by authologous stem cell transplantation has been proposed. In contrast to patients with a high percentage of aberrant $\mathrm{T}$ cells, patients with RCD I seem to profit from treatment with immunosuppressives.

Some evidence indicates that individuals with a sibling affected with coeliac disease also have an excess risk for non-Hodgkin lymphoma, which suggests a shared susceptibility [42].

\section{Treatment}

Other approaches that would reduce the need for dieting are being studied but are not yet ready for clinical application. These include the use of gluten-degrading enzymes to be ingested with meals, the development of alternative gluten-free grains by genetic modification, the use of substrates regulating intestinal permeability to prevent gluten entry across the epithelium, and different forms of immunotherapy [43]. Prolyl endopeptidases from various bacterial and non-bacterial species appear to be able to achieve gluten detoxification (glutenase therapy). The use of antagonists of zonulin, a peptide involved in the formation of tight junctions, has shown promising preliminary results, and studies with peptides that could block the binding of deamidated gliadin peptides to DQ2 may have great potential [44].

Coeliac disease is now also well recognized as a disorder that can affect other segments of the gastrointestinal tract (lymphocytic gastritis and lymphocytic colitis can be part of the condition) and it has even been classed as a multisystem or multi-organ disorder that may affect extra-intestinal organs, such as the skin, heart, nervous system and liver $[45,46]$.

\section{Implications for clinical practice}

The clinical presentation of coeliac disease is highly variable, and the disease is now recognized as a multisystem disorder. Recent advances show that the disease is much more common than previously suspected, and that diagnosis should be considered not only when there are gastrointestinal symptoms, but also when extraintestinal manifestations such as anaemia or osteoporosis are seen. Screening is indicated in relatives of patients with established coeliac disease and in patients at risk, such as those with type 1 diabetes and other autoimmune diseases, as well as various neurological syndromes including unexplained peripheral neuropathy, epilepsy with occipital calcifications and ataxia. Testing for coeliac disease is also needed in patients with Down and Turner syndrome.

In most patients diagnosis is reached easily with serology and duodenal biopsy. Immunohistochemistry for CD3 on small intestinal biopsy samples may also help diagnosis. Roughly $10 \%$ of patients are difficult to diagnose because of lack of concordance between serology and histology, and in these cases testing for HLA-DQ may be helpful.

Diet therapy remains the cornerstone of treatment. A poor response to the diet is common and requires extensive evaluation for dietary mistakes and to rule out 
complications. It is not proven, however, that lifelong treatment prevents complications.

Adenocarcinoma and lymphoma are major complications of coeliac disease, and RCD II is associated with a much more severe clinical presentation and prognosis. Recent advances suggest that immunophenotyping of $\mathrm{T}$ cells from biopsies can help predict which patients will develop overt lymphoma.

\section{Abbreviations}

EATL, enteropathy-associated T-cell lymphoma; EMA, endomysial antibodies; ESPGAN, European Society for Paediatric Gastroenterology and Nutrition; HLA, human leukocyte antigen; IEL, intra-epithelial lymphocyte; IFN, interferon; IgA, immunoglobulin A; RCD, refractory coeliac disease; Th, T helper; TLR, Toll-like receptor; tTG, tissue transglutaminase.

\section{Competing interests}

The authors declare that they have no competing interests.

\section{References}

I. Gee S: On the coeliac affection. St Bartholomews Hospital Report 1888, 24:17-20.

2. Dicke WK: Coeliac Disease: Investigation of the harmful effects of certain types of cereal on patients with coeliac disease. Doctoral Thesis, University of Utrecht, Netherlands 195I.

3. Meeuwisse GW: Diagnostic criteria in celiac disease. Acta Paediatr Scand 1970, 59:46I-3.

4. Greco L, Romino R, Coto I, Di Cosmo N, Percopo S, Maglio M, Paparo F, Gasperi V, Limongelli MG, Cotichini R, D'Agate C, Tinto N, Sacchetti L, Tosi R, Stazi MA: The first large population based twin study of coeliac disease. Gut 2002, 50:624-8.

5. Ivarsson A, Hernell O, Stenlund H, Persson LA: Breast-feeding protects against celiac disease. Am J Clin Nutr 2002, 75:9|4-2I.

6. Koning F, Schuppan D, Cerf-Bensussan N, Sollid LM: Pathomechanisms in celiac disease. Best Pract Res Clin Gastroenterol 2005, 19:373-87.

7. Hill ID: What are the sensitivity and specificity of serologic tests for celiac disease? Do sensitivity and specificity vary in different populations? Gastroenterology 2005, I 28:S25-S32.

8. Hummel S, Hummel M, Banholzer J, Hanak D, Mollenhauer U, Bonifacio E, Ziegler AG: Development of autoimmunity to transglutaminase $C$ in children of patients with type I diabetes: relationship to islet autoantibodies and infant feeding. Diabetologia 2007, 50:390-4.

9. Santaolalla $R$, Fernández-Bañares $F$, Rodríguez $R$, Alsina $M$, Rosinach $M$, Mariné $M$, Farré $C$, Salas $A$, Forné $M$, Loras $C$, Espinós J, Viver JM, Esteve M: Diagnostic value of duodenal antitissue transglutaminase antibodies in gluten-sensitive enteropathy. Aliment Pharmacol Ther 2008, 27:820-9.

10. Mee AS, Burke M, Vallon AG, Newman J, Cotton PB: Small bowel biopsy for malabsorption: comparison of diagnostic adequacy of endoscopic forceps and capsule biopsy specimens. $\mathrm{Br}$ Med J (Clin Res Ed) 1985, 291:769-72.

II. Green PH, Rostami K, Marsh MN: Diagnosis of coeliac disease. Best Pract Res Clin Gastroenterol 2005, 19:389-400.

12. Dickson BC, Streutker CJ, Chetty R: Coeliac disease: an update for pathologists. J Clin Pathol 2006, 59:1008-16.
13. Marsh MN: Gluten, major histocompatibility complex and the small intestine. A molecular and immunobiologic approach to the spectrum of gluten sensitivity ('celiac sprue'). Gastroenterology 1992, 102:330-54.

14. Oberhuber G, Granditsch G, Vogelsang H: The histopathology of coeliac disease: time for a standardized report scheme for pathologists. Eur J Gastroenterol Hepatol 1999, I I:I I85-94.

15. Corazza GR, Villanacci V: Coeliac disease. J Clin Pathol 2005, 58:573-4.

16. Veress B, Franzén L, Bodin L, Borch K: Duodenal intraepithelial lymphocyte-count revisited. Scand J Gastroenterol 2004, 39: 138-44.

17. Catassi C, Fasano A: Celiac disease. Curr Opin Gastroenterol 2008, 24:687-91.

18. Catassi C, Bearzi I, Holmes GK: Association of celiac disease and intestinal lymphomas and other cancers. Gastroenterology 2005, I 28:S79-S86.

19. van Heel DA, Hunt K, Greco L, Wijmenga C: Genetics in coeliac disease. Best Pract Res Clin Gastroenterol 2005, 19:323-39.

20. Kagnoff MF: Overview and pathogenesis of celiac disease. Gastroenterology 2005, I28:SI0-8.

21. van Heel DA, Franke L, Hunt KA, Gwilliam R, Zhernakova A, Inouye M, Wapenaar MC, Barnardo MC, Bethel G, Holmes GK, Feighery C, Jewell D, Kelleher D, Kumar P, Travis S, Walters JR, Sanders DS, Howdle P, Swift J, Playford RJ, McLaren WM, Mearin ML, Mulder CJ, McManus R, McGinnis R, Cardon LR, Deloukas P, Wijmenga $C$ : A genome-wide association study for celiac disease identifies risk variants in the region harbouring IL2 and IL2 I. Nat Genet 2007, 39:827-9.

FI000 Factor 3.0 Recommended Evaluated by Mark Anderson 5 Jul 2007

22. Zhernakova A, van Diemen CC, Wijmenga C: Detecting shared pathogenesis from the shared genetics of immune-related diseases. Nat Rev Genet 2009, 10:43-55.

23. Hunt KA, Zhernakova A, Turner G, Heap GA, Franke L, Bruinenberg M, Romanos J, Dinesen LC, Ryan AW, Panesar D, Gwilliam R, Takeuchi F, McLaren WM, Holmes GK, Howdle PD, Walters JR, Sanders DS, Playford RJ, Trynka G, Mulder CJ, Mearin ML, Verbeek WH, Trimble V, Stevens FM, O'Morain C, Kennedy NP, Kelleher D, Pennington DJ, Strachan DP, McArdle WL et al:: Newly identified genetic risk variants for celiac disease related to the immune response. Nat Genet 2008, 40:395-402.

FI000 Factor 6.6 Must Read

Evaluated by Nadine Cerf-Bensussan 08 Apr 2008, Nicola Jones

OI Jul 2008, Helena Tlaskalova-Hogenova OI Dec 2008

24. Wolters VM, Wijmenga C: Genetic background of celiac disease and its clinical implications. Am J Gastroenterol 2008, I 03:190-5.

25. Lettre G, Rioux JD: Autoimmune diseases: insights from genome-wide association studies. Hum Mol Genet 2008, I7: RII6-2I.

26. Fina D, Sarra M, Caruso R, Del Vecchio Blanco G, Pallone F, MacDonald TT, Monteleone G: Interleukin 2 I contributes to the mucosal $\mathbf{T}$ helper cell type I response in coeliac disease. Gut 2008, 57:887-92.

27. Szebeni B, Veres G, Dezsofi A, Rusai K, Vannay A, Bokodi G, Vásárhelyi B, Korponay-Szabó IR, Tulassay T, Arató A: Increased mucosal expression of Toll-like receptor (TLR)2 and TLR4 in coeliac disease. J Pediatr Gastroenterol Nutr 2007, 45:187-93.

28. Baldassarre M, Laneve AM, Grosso R, Laforgia N: Celiac disease: pathogenesis and novel therapeutic strategies. Endocr Metab Immune Disord Drug Targets 2008, 8:152-8.

29. Setty M, Hormaza L, Guandalini S: Celiac disease: risk assessment, diagnosis, and monitoring. Mol Diagn Ther 2008, I2:289-98.

30. Meresse B, Verdier J, Cerf-Bensussan N: The cytokine nterleukin 21: a new player in coeliac disease. Gut 2008, 57:879-8I.

3I. Fasano A, Berti I, Gerarduzzi T, Not T, Colletti RB, Drago S, Elitsur Y, Green PH, Guandalini S, Hill ID, Pietzak M, Ventura A, Thorpe M, 
Kryszak D, Fornaroli F, Wasserman SS, Murray JA, Horvath K: Prevalence of celiac disease in at-risk and not-at-risk groups in the United States: a large multicenter study. Arch Intern Med 2003, 163:286-92.

32. Rubio-Tapia A, Van Dyke CT, Lahr BD, Zinsmeister AR, El-Youssef M, Moore SB, Bowman M, Burgart LJ, Melton LJ 3rd, Murray JA: Predictors of family risk for celiac disease: a population-based study. Clin Gastroenterol Hepatol 2008, 6:983-7.

\section{Changes Clinical Practice}

FI000 Factor 3.0 Recommended

Evaluated by Karel Geboes 0I Oct 2008

33. Ivarsson A: The Swedish epidemic of coeliac disease explored using an epidemiological approach-some lessons to be learnt. Best Pract Res Clin Gastroenterol 2005, 19:425-40.

34. Fasano A, Catassi C: Coeliac disease in children. Best Pract Res Clin Gastroenterol 2005, 19:467-78.

35. Caprai S, Vajro P, Ventura A, Sciveres M, Maggiore G; SIGENP Study Group for Autoimmune Liver disorders in Celiac Disease: Autoimmune liver disease associated with celiac disease in childhood: a multicenter study. Clin Gastroenterol Hepatol 2008, 6:803-6.

36. Cosnes J, Cellier C, Viola S, Colombel JF, Michaud L, Sarles J, Hugot JP, Ginies LL, Dabadie A, Mouterde O, Allez M, Nion-Larmurier I; Groupe D'Etude et de Recherche Sur la Maladie Coeliaque: Incidence of autoimmune diseases in celiac disease: protective effect of the gluten-free diet. Clin Gastroenterol Hepatol 2008, 6:753-8.

37. Akram S, Murray JA, Pardi DS, Alexander GL, Schaffner JA, Russo PA, Abraham SC: Adult autoimmune enteropathy: Mayo Clinic Rochester experience. Clin Gastroenterol Hepatol 2007, 5: 1282-90.

FI000 Factor 3.0 Recommended

Evaluated by Karel Geboes 30 Nov 2007

38. Catassi C, Bearzi I, Holmes GK: Association of celiac disease and intestinal lymphomas and other cancers. Gastroenterology 2005, I 28(4 Suppl I):S79-S86.
39. Verbeek WH, Van De Water JM, Al-Toma A, Oudejans J], Mulder C], Coupé VM: Incidence of enteropathy-associated T-cell lymphoma: a nation-wide study of a population-based registry in The Netherlands. Scand J Gastroenterol 2008, 43:1322-8.

40. Geboes K, De Wolf Peeters C: Neoplasms of the small intestine. In Gastrointestinal and Liver Tumors. Edited by Scheppach W. Bresalier RS, Tytgat GN. Berlin: Springer; 2003:83-98.

4I. Malamut G, Afchain P, Verkarre V, Lecomte T, Amiot A, Damotte D, Bouhnik Y, Colombel JF, Delchier JC, Allez M, Cosnes J, LavergneSlove A, Meresse B, Trinquart L, Macintyre E, Radford-Weiss I, Hermine O, Brousse N, Cerf-Bensussan N, Cellier C: Presentation and long-term follow-up of refractory celiac disease: comparison of type I with type II. Gastroenterology 2009, I36:8I-90.

42. Gao Y, Kristinsson SY, Goldin LR, Björkholm M, Caporaso NE, Landgren O: Increased risk for non-Hodgkin lymphoma in individuals with celiac disease and a potential familial association. Gastroenterology 2009, 136:91-8.

43. Green PH, Cellier C: Celiac disease. N EnglJ Med 2007, 357: I 73 I-43.

44. Gass J, Bethune MT, Siegel M, Spencer A, Khosla C: Combination enzyme therapy for gastric digestion of dietary gluten in patients with celiac sprue. Gastroenterology 2007, 133:472-80.

45. Rostom A, Murray JA, Kagnoff MF: American Gastroenterological Association (AGA) Institute technical review on the diagnosis and management of celiac disease. Gastroenterology 2006, I3 I:| $98 \mid-2002$.

46. Ludvigsson JF, Olén O, Bell M, Ekbom A, Montgomery SM: Coeliac disease and risk of sepsis. Gut 2008, 57:1074-80.

Changes Clinical Practice

FI000 Factor 6.4 Must Read

Evaluated by Karel Geboes 05 Aug 2008, Klaus Monkemuller 20 Oct 2008 